\title{
Skin And Soft Tissue Infections Associated with Methicillin Resistant Staphylococcus Aureus, Esbl, Amp C And Metallo B- Lactamase Producing Bacilli In A Tertiary Care Hospital
}

\author{
Dr. Jeevan Shetty* \\ *Associate Professor,Department Of Microbiology, G.S Medical College And Hospital (Chaudhary Charan \\ Singh University), Pilkhuwa, Uttar Pradesh, India.
}

\begin{abstract}
Introduction: Skin and soft tissue infections (SSTI's) are commonly caused by both gram positive and gram negative bacteria. The aim of the study was to investigate the presence of methicillin resistant Staphylococcus aureus (MRSA), Extended Spectrum Beta Lactamase (ESBL), Amp C and Metallo $\beta$-lactamase producing gram negative bacilli from clinical isolates obtained from patients attending G.S Medical College and Hospital, Pilkhuwa, Uttar Pradesh, India.

Materials and Methods: A total of 263 clinical isolates obtained from skin and soft tissue infections were processed from September 2016 to May 2017 in this study. The isolates were identified by conventional microbiological methods and Antimicrobial susceptibility testing was done on Mueller Hinton Agar plate by Kirby Bauer's disc diffusion method. All the organisms suspected to be methicillin resistant Staphylococcus aureus (MRSA) among gram positive cocci and those gram negative bacilli producing ESBL were detected by phenotypic confirmatory disc diffusion test (PCDDT) as per Clinical and Laboratory Standard Institute (CLSI) criteria. Amp $C$ detection in gram negative bacilli was done by using Amp C Disc test while Metallo $\beta$ lactamase production was detected by Imipenem-Ethylene Diamine Tetra Acetic acid (EDTA) combined disc test.

Result: Out of the 263 clinical isolate tested, 162(61.6\%) were gram positive cocci and 101 (38.4\%) gram negative bacilli. MRSA accounted for $16 \%$ of total isolates. Among gram negative bacilli, $22.8 \%$ were found to be pure ESBL producers by the PCDDT method and $23.8 \%$ pure Amp C producers by Amp C Disc test.Metallo $\beta$-lactamases (MBL)accounted for $16.8 \%$ of gram negative isolates. Co-expression of ESBL and AmpC was observed in $4.9 \%$ while in $8.9 \%$ isolates AmpC production was associated with MBL production. ESBL production was predominantly noticed in Escherichia coli and Proteus mirabilis while Amp C production was most common in Klebsiella spp followed by Pseudomonas aeruginosa. One third of Acinetobacter isolates were found to be pure metallo $\beta$-lactamase producers.

Conclusion: Since MRSA, ESBL's, Amp C and MBL producing gram negative bacilli are on a constant rise, it is very necessary to detect all the organisms isolated from cases of SSTI's for these mechanism of resistance. Regular detection of these bacteria in clinical microbiology laboratory helps in guiding the physicians regarding empirical use of antibiotics and also in incorporating strategies for control measures to prevent spread of drug resistant organisms.
\end{abstract}

Keywords: Amp C, ESBL, Gram positive cocci, Gram negative bacilli, MRSA

\section{Introduction}

Skin and soft tissue infections involves skin, subcutaneous fat, fascial layers and musculotendinous structures. Infections are classified as simple (uncomplicated) or complicated (necrotizing or nonnecrotizing), or as suppurative or nonsuppurative. Also based on their severity, presence of co-morbid conditions and on the nature of therapeutic intervention it can be classified. Common SSTI's are cellulitis, erysipelas, furunculosis, folliculitis, carbuncles, abscesses, deep abscess, decubitus ulcers, necrotizing fasciitis, gangrene, perianal infections, diabetic foot ulcers and infections due to animal or human bite [1]. Usually the pathogens implicated in SSTI's include Staphylococcus aureus (S. aureus), $\beta$ - hemolytic streptococci, Pseudomonas aeruginosa, Enterococcus, Clostridium perfringens, Escherichia coli(E. coli) and other members of the family Enterobacteriaceae.The last four decades have seen a global epidemic of MRSA and the boundary between hospital and community acquired MRSA is becoming more blurred [2]. Immunocompromised patients who are very ill require broad spectrum empirical agents such as vancomycin and linezolid to take care of MRSA. The utility of macrolide in pyoderma therapy has lessened in areas where erythromycin resistant strains of S. aureus and S. pyogenes are prevalent[3]. 
Antibiotic resistance among Gram negative bacilli (GNB) is of great concern due to the organism's ability to mutate and acquire plasmids as well as other mobile genetic elements encoding resistance. The original method of $\beta$-lactamase categorization is the Ambler classification which divides the enzymes into 4 classes (A, B, C and D) based on molecular structure. ESBL's are Class A $\beta$ - lactamases which are defined as plasmid mediated enzymes capable of hydrolyzing oxyimino-Cephalosporins, Monobactams but not Cephamycins such as cefoxitin or Carbapenems. They are inhibited by $\beta$-lactamases inhibitors such as Clavulanic acid. Among the genotypes of ESBL's, the most common are SHV, TEM, CTX-M types. Bush et al in 1995 devised a classification of $\beta$-lactamases based upon their functional characteristics and substrate profile which is widely used now. Group 1 includes cephalosporinases (Amp C) which are not inhibited by clavulanic acid and also capable of hydrolyzing Cephamycins. The large Group 2 includes the ESBL's which are generally inhibited by clavulanic acid .Hydrolysis of cephamycins such as cefoxitin is a property that helps to distinguish Amp C's from ESBL's. Metallo $\beta$-lactamases belonged to Group 3 for which the preferred substrate is Carbapenems[4]. Severity of SSTI's is determined by several factors such as extent and intensity of inflammation, distribution and depth of infection, significant co-morbidities and based on systemic inflammatory response [5]. Bacterial adherence to host cells, invasion of tissue with evasion of host defences and elaboration of toxins are three main steps in development of SSTI's[6]. SSTI's are classified as complicated if it is associated with signs and symptoms such as fever, hypothermia, tachycardia (>100 beats/min) and hypotension (systolic blood pressure $<90 \mathrm{~mm} \mathrm{Hg}$ below baseline) [7]. Other than underlying co-morbidities, occurrence of multi-drug resistant bacteria contributes to the complications in management of complicated SSTI's [8].

Physicians need to be aware of the resistance pattern of pathogens causing skin and soft tissue infections prevalent locally. There is no studies about the prevalence of MRSA, ESBL, Amp C and metallo $\beta$ lactamases (MBL) involved in SSTI's in this region. In this background the study was conducted which helps in the proper treatment of the patients and prevent further development of drug resistance in bacteria.

\section{Material and methods}

A prospective observational study was performed over a period of nine months from September 2016 to May 2017in the Department of Microbiology, G.S Medical College and Hospital, Pilkhuwa, Uttar Pradesh. The study was approved by the ethical committee of the institution and each patient gave informed consent prior to participation in the study. Total number of 162 gram positive cocci and 101 gram negative bacilli were isolated from cases of SSTI's and are identified according to conventional microbiological methods [9, 10].After the isolates were identified by standard guidelines, antimicrobial susceptibility testing was done by Kirby- Bauer disk diffusion method on Mueller- Hinton agar plates(Himedia Lab, Mumbai)[11].

\section{Detection of Methicillin resistance in Staphylococcus aureus:}

Methicillin resistance in S. aureus was detected based on Clinical and Laboratory Standards Institute (CLSI) recommendations using cefoxitin $(30 \mu \mathrm{g})$ disc on a swab inoculated Mueller Hinton Agar (MHA) plate and incubated at a temperature of $35^{\circ} \mathrm{C}$ for 24 hours [12]. S. aureus ATCC 25923 was used for the purpose of quality control [Fig-1]. Methicillin resistance (MRCONS) was also observed in coagulase negative staphylococci (CONS).

\section{Detection of Extended Spectrum Beta-Lactamase (ESBL) by phenotypic confirmatory disc diffusion test (PCDDT):}

The gram negative bacterial isolates which showed resistance or reduced zone of inhibition to any of the third generation cephalosporins were selected. Disks of Cefotaxime $(30 \mu \mathrm{g})$ and Ceftazidime $(30 \mu \mathrm{g})$ alone and in combination with $\beta$-lactamase inhibitor clavulanic acid $(10 \mu \mathrm{g})$ were used to perform the test. Cefotaxime $(30 \mu \mathrm{g})$ and Cefotaxime- clavulanic acid $(30 \mu \mathrm{g} / 10 \mu \mathrm{g})$ and Ceftazidime $(30 \mu \mathrm{g})$ and Ceftazidime- clavulanic acid $(30 \mu \mathrm{g} / 10 \mu \mathrm{g})$ were placed on the MHA plate and these plates were incubated overnight at $37^{\circ} \mathrm{C}$. An increase in zone diameter of $\geq 5 \mathrm{~mm}$ with combination disc in comparison to third generation cephalosporin disc alone was considered to be an ESBL producer [Fig-2]. Klebsiella pneumoniae ATCC 700603 and E. Coli ATCC 25922 were used as ESBL positive and negative controls [12].

\section{Amp C disc test:}

All Gram negative bacilli isolates with reduced susceptibility to cefoxitin $(\leq 18 \mathrm{~mm})$ and resistant to third generation Cephalosporins were tested for Amp C disc test. Amp C disks prepared with sterile paper discs are moistened with $20 \mu 1$ sterile saline and several colonies of test organisms were applied on the disc. A lawn culture of E. coli ATCC 25922 is prepared on Mueller Hinton Agar plate and $30 \mu \mathrm{g}$ of cefoxitin discs was placed on it. Now inoculated Amp C discs are placed almost touching the cefoxitin discs and one negative control was put up. The plates are

DOI: $10.9790 / 0853-1606070814 \quad$ www.iosrjournals.org $\quad 9 \mid$ Page


inverted and incubated overnight at $35^{\circ} \mathrm{C}$ in ambient air [Fig-3]. After incubation the plates were examined for indentation or flattening of the zone of inhibition beside Amp C discs (positive result). The absence of a distortion or no flattening is considered as negative for Amp C production [13, 14].

\section{Detection of metallo $\square$-lactamase:}

The isolates showing a zone of inhibition $\leq 16 \mathrm{~mm}$ or which demonstrated heaping, or if the zone was $>16 \mathrm{~mm}$ but $\leq 20 \mathrm{~mm}$ to Imipenem were selected after performing modified Hodge test. A 0.5 M EDTA solution was prepared by dissolving $186.1 \mathrm{gm}$ of EDTA. $2 \mathrm{H}_{2} \mathrm{O} \mathrm{IN} 1000 \mathrm{ml}$ of distilled water and its $\mathrm{pH}$ adjusted to 8.0 using $\mathrm{NAOH}$ and sterilized by autoclaving. One disc of imipenem $(10 \mu \mathrm{g})$ alone and another with imipenem $(10 \mu \mathrm{g})$ in combination with EDTA solution $(750 \mu \mathrm{g})$ were placed beside on the lawn culture of suspected isolate and incubated overnight at $37^{\circ} \mathrm{C}$. A plain disc with EDTA solution $(750 \mu \mathrm{g})$ alone served as negative control[Fig4].Then if the increase in zone of inhibition with Imipenem and EDTA disc was $\geq 7 \mathrm{~mm}$ than the Imipenem disc alone, it was considered as metallo $\beta$-lactamase (MBL) producer[15, 16].

\section{Results}

A total of 263 clinical isolates were obtained from the SSTI's which occurred over a period of nine months. Among them, $162(61.6 \%)$ were gram positive cocci and 101 (38.4\%) gram negative bacilli. S. aureus accounted for $28.9 \%$ of the total positive isolates from SSTI's and $16 \%$ were MRSA. The other Gram positive cocci isolated were $\beta$ - hemolytic streptococci (9.1\%), Enterococcus faecalis (3.8\%), CONS (2.3\%) and MRCONS (1.5)\% . The predominant Gram negative bacilli was Pseudomonas aeruginosa(14.5\%), followed by Klebsiella species (11.4\%), Acinetobacter species (6.8\%), Escherichia coli (3.4\%) and Proteus mirabilis (2.3\%) [Table 1].

All the 101 isolates of Gram negative bacilli were screened for ESBL and AmpC production. ESBL detection by PCDDT found 23(22.8\%) isolates to be sole ESBL producers while 24(23.8\%) isolates being AmpC producers. MBL activity was observed to be the sole reason in 17 isolates (16.8\%). Co-expression of ESBL and AmpC was observed in 5 isolates (4.9\%) while in 9 isolates (8.9\%) AmpC production was associated with MBL production. ESBL production was predominantly noticed in E. coli and P. mirabilis while AmpC production occurred more among Klebsiella and $\mathrm{P}$. aeruginosa isolates. MBL production was observed among Acinetobacter, P. aeruginosa and Klebsiella isolates and one-third of Acinetobacter were pure MBL producers. No AmpC and MBL activity seen among E. coli and P. mirabilis isolates[Table 2].

Distribution of ESBL, AmpC $\beta$ - lactamase and Metallo $\beta$ - lactamase producing Gram-negative bacteria and their co-existence is depicted in the chart [Fig-5].

\section{Tables And Figures}

Table 1: Bacterial pathogens isolated from Skin and Soft Tissue Infections

\begin{tabular}{|l|l|l|}
\hline Percent & Frequency & Bacterial isolate \\
\hline 61.6 & 162 & Gram positive cocci \\
\hline 28.9 & 76 & S. aureus (MSSA) \\
\hline 16 & 42 & MRSA \\
\hline 9.1 & 24 & $\beta$ - hemolytic Streptococci \\
\hline 3.8 & 10 & Enterococcus faecalis \\
\hline 2.3 & 6 & CONS \\
\hline 1.5 & 4 & MRCONS \\
\hline 38.4 & 101 & Gram negative bacilli \\
\hline 14.5 & 38 & Pseudomonas aeruginosa \\
\hline 11.4 & 30 & Klebsiella species \\
\hline 6.8 & 18 & Acinetobacter species \\
\hline 3.4 & 9 & Escherichia coli \\
\hline 2.3 & 6 & Proteus mirabilis \\
\hline 100 & 263 & Total \\
\hline
\end{tabular}

Table 2: Prevalence of ESBL, Amp C and Metallo $\beta$-lactamase producers from SSTI's

\begin{tabular}{|l|l|l|l|l|l|l|l|}
\hline $\begin{array}{l}\text { Non- } \\
\begin{array}{l}\text { } \\
\text { productamase }\end{array}\end{array}$ & Amp C+MBL & $\begin{array}{l}\text { ESBL+ } \\
\text { Amp C }\end{array}$ & $\begin{array}{l}\text { MBL } \\
\text { positiv } \\
\text { e }\end{array}$ & $\begin{array}{l}\text { Amp C } \\
\text { positive }\end{array}$ & $\begin{array}{l}\text { ESBL } \\
\text { positiv } \\
\text { e }\end{array}$ & $\begin{array}{l}\text { Number of } \\
\text { isolates } \\
\text { screened }\end{array}$ & Gram negative bacilli \\
\hline 10 & 3 & 3 & 8 & 10 & 4 & 38 & $\begin{array}{l}\text { Pseudomonas } \\
\text { aeruginosa }\end{array}$ \\
\hline 7 & 2 & 2 & 3 & 11 & 5 & 30 & Klebsiella species \\
\hline 3 & 4 & nil & 6 & 3 & 2 & 18 & Acinetobacter species \\
\hline 3 & nil & nil & nil & nil & 6 & 9 & Escherichia coli \\
\hline nil & nil & nil & nil & nil & 6 & 6 & Proteus mirabilis \\
\hline 23 & 9 & 5 & 17 & 24 & 23 & 101 & Total \\
\hline
\end{tabular}



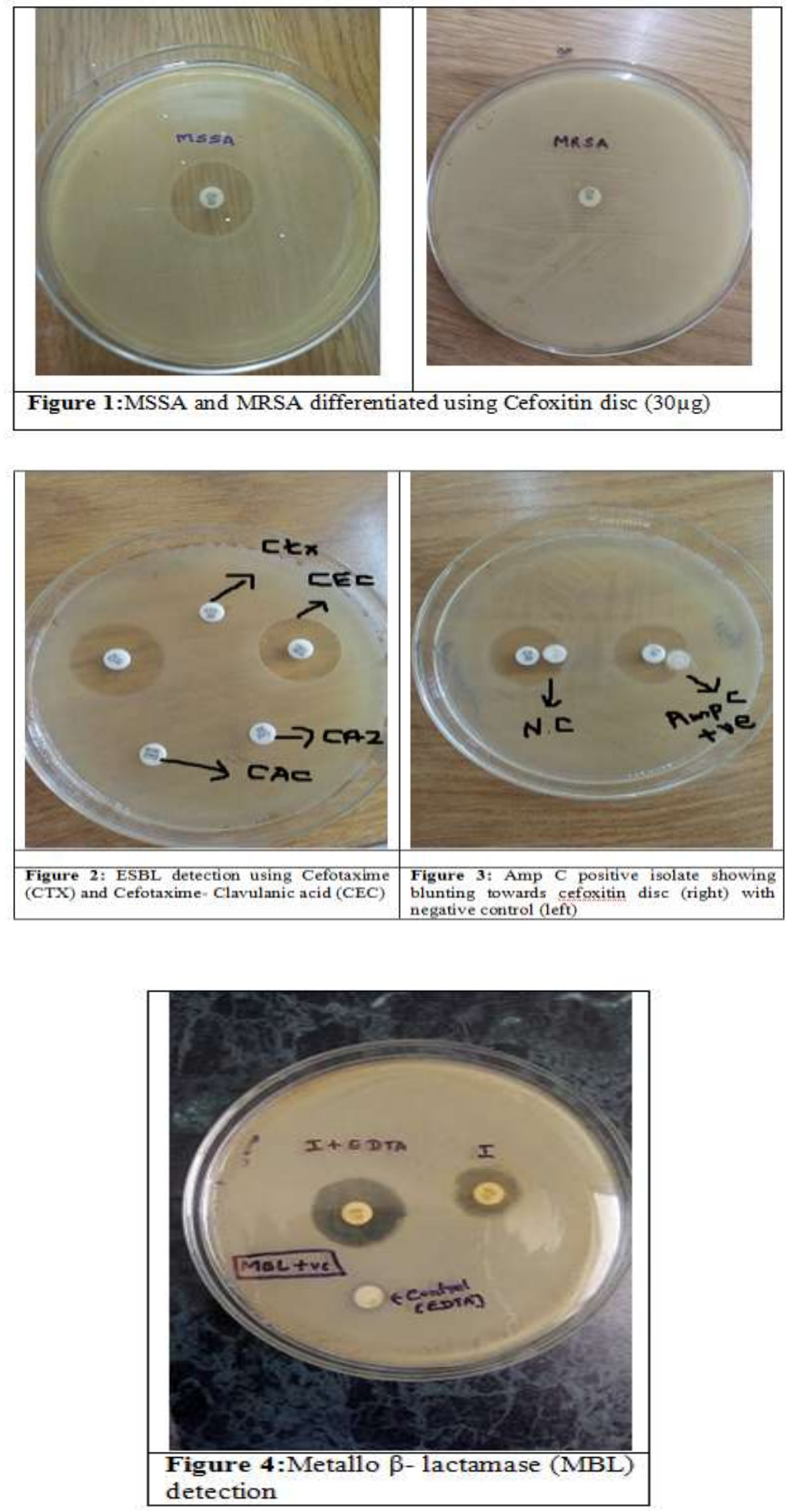


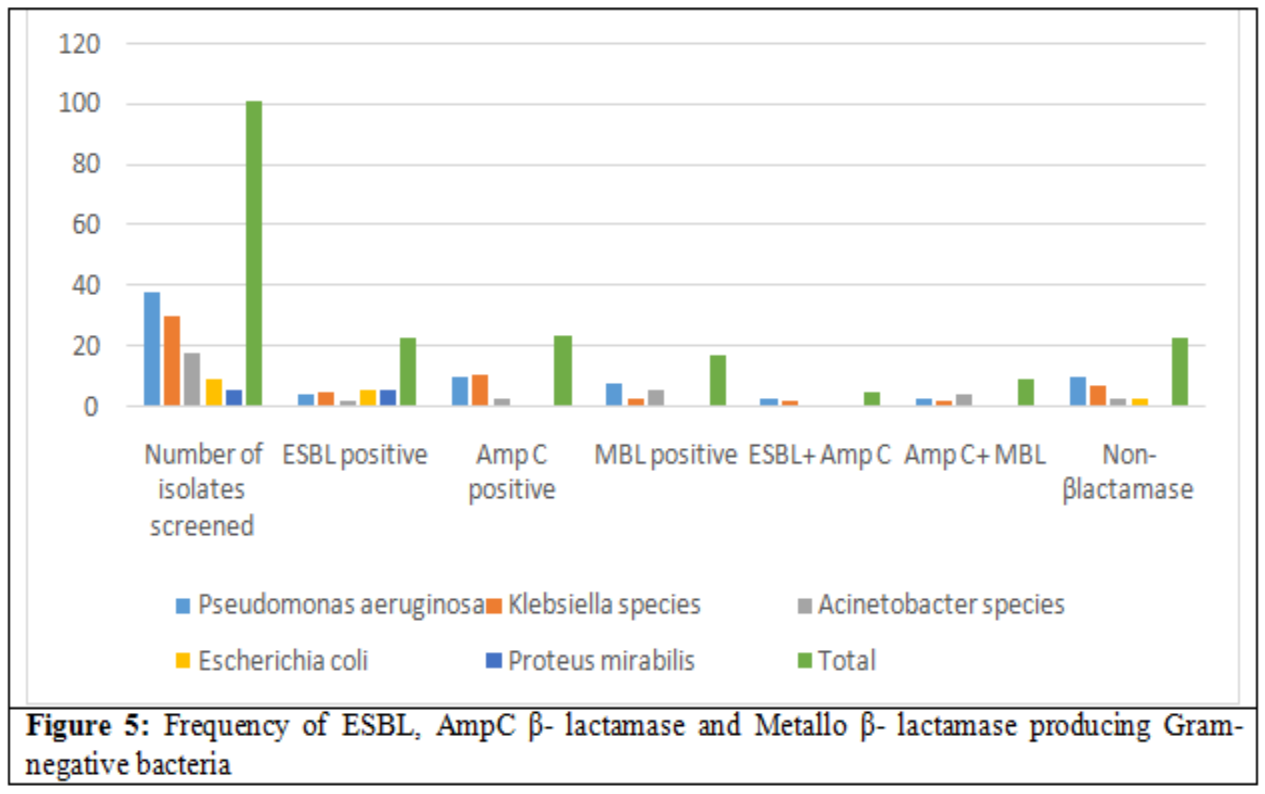

\section{Discussion}

SSTI's in our hospital is contributed by both gram positive cocci and gram negative bacilli. Several studies have highlighted that gram positive cocci and in particular S. aureus as the most common pathogen and significant amount being MRSA. Studies done across Europe has found S. aureusin $71 \%$ and MRSA contributing almost $22 \%$ of cases. A similar study conducted by Indian Network for Surveillance of Antimicrobial Resistance group in 15 Indian tertiary care centres over two year period has found methicillin resistance to be $41 \%$ which included majority of isolates from SSTI's [17]. Another study done in Bosnia has found equal proportion of MSSA and MRSA in SSTI's where 39.5\% were confirmed to be MRSA by polymerase chain reaction (PCR) assay [18]. Highest prevalence of MRSA was observed from pus samples $(66.03 \%)$ in another study followed by in urine $(11.45 \%)$ and blood/ catheter tips $(9.16 \%)$. Also an overall increase in MRSA prevalence in the hospital was observed which was $16.5 \%$ in 2009 and reached $37.5 \%$ in 2012 [19].S. aureus was the commonest organism isolated from SSTI's (37.5\%) and MRSA accounted for $40.25 \%$ among S. aureus in a study done in Rajasthan [20]. In this study 16\% isolates were MRSA and there is a need to monitor and implement infection control measures like hand washing, aseptic techniques and screening health care personnel.

Study on the pattern of bacterial pathogens from surgical site infections and their susceptibility done in Ethiopia found Gram negative bacilli $(73.1 \%)$ more than Gram positive cocci $(28.9 \%)$. E. coli $(23.1 \%)$ was the most common organism isolated closely followed by Acinetobacter (22.1\%) and S. aureus (18.3\%) [21]. In this study gram positive cocci (61.6\%) predominated gram negative bacilli (38.4\%). In contrast a study on SSTI's done at Vijayapura found $57.40 \%$ were gram negative bacilli and only $42.59 \%$ were gram positive cocci [22]. But similar to this study P. aeruginosa predominated among gram negative bacilli. ESBL producing gram negative bacilli has emerged as a major challenge in hospitalized as well as community based patients.Plasmid mediated AmpC $\beta$ - lactamases have been noticed in many gram negative bacilli which includes Klebsiella spp, Salmonella spp, C. freundii, E. aerogenes, P. mirabilis and E. coli. The transmissible Carbapenemases enzymes are known to be acquired by important pathogens such as P. aeruginosa, A. baumanii and members of the family Enterobacteriaceae [23].

In this study ESBL detection by PCDT found $22.8 \%$ isolates to be sole ESBL producers and predominantly noticed in E. coli and P. mirabilis. AmpC production was solely observed in $23.8 \%$ isolates while MBL activity in $16.8 \%$ isolates. ESBL production was observed in $55.5 \%$ of the isolates and AmpC in $35.18 \%$ isolates among gram negative bacilli obtained from diabetic foot ulcer infections in a study conducted in Chennai [24]. ESBL activity has also been noticed in Enterobacter spp where $48.9 \%$ of E. cloacae and $14.3 \%$ of E. aerogenes were ESBL producers [25]. ESBL production by P. aeruginosa isolates from ocular infections have prompted alteration in the management protocol of such infections [26]. In one centre Multiplex Polymerase Chain Reaction (PCR) done as a confirmatory step for detection of AmpC and MBL's found P. aeruginosa as the most common isolated gram negative strain positive for both AmpC and MBL [16].Carbapenems such as meropenem have been used widely against mixed multidrug resistant pathogens involved in complicated SSTI's for a long time and studies have suggested to use higher doses of meropenem if involved pathogen is $\mathrm{P}$. aeruginosa [27]. But increasing MBL producing P. aeruginosa from SSTI's is a matter of concern. Other gram negative bacterias such as Stenotrophomonas maltophilia and Elizabethkingia meningoseptica which have 
intrinsic resistance to Carbapenems have to be borne in mind [28]. In this study co-production of ESBL and Amp Cwere observed in $4.9 \%$ isolates while Amp C and MBL were observed in $8.9 \%$ isolates of gram negative bacilli. ESBL and Amp C co-producers was observed similarly in one study where it accounted for $5.5 \%$ of gram negative bacilli [29].In another study ESBL and Amp C co production was observed in 9.7\% isolates and Amp C and MBL coproducers in $6.2 \%$ isolates [14]. Molecular characterization done on carbapenem resistant Enterobacteriaceae (CRE) has found co-carriage of ESBL's, AmpC and New Delhi metallo $\beta$-lactamase-1 as high as $26.3 \%$ in a study on CRE [30].

\section{Conclusion}

Microbiology laboratories across globe should closely monitor resistant pathogens in their locality and reporting of MRSA, ESBL's, AmpC and MBL should be done regularly. Treatment strategy of SSTI's should be based on antibiogram results. This study was limited by the fact that isolates could not be further confirmed by genotypic methods due to limited sources. Phenotypic detection definitely helps us in understanding the mechanism of resistance existing in pathogens locally and to implement strategies to curb spread of such infections in a hospital.

\section{References}

[1]. Kalyanakrishnan R, Salinas RC, Higuita NIA. Skin and Soft tissue infections. American Family Physician 92(6), 2015,474-83.

[2]. Dryden MS. Skin and soft tissue infection: Microbiology and epidemiology. Int J Antimicrobial Agents 34(1), 2009, S2-S7.

[3]. Stevens DL, Bisno AL, Chambers HF, Everett ED, Dellinger P, Goldstein EJ et al. Practice guidelines for the diagnosis and management of Skin and soft tissue infections. Clin Infect Dis 41, 2005, 1373-406.

[4]. Thenmozhi S, Moorthy K, Sureshkumar BT, Suresh M. Antibiotic resistance mechanism of ESBL producing Enterobacteriaceae in clinical field: A Review. Int J Pure App Biosci2(3), 2014, 207-226.

[5]. Seaton RA. Skin and soft tissue infection diagnosis and management. Clinical Pharmacist, , 1,2009, 13-22.

[6]. Ki V, Rotstein C. Bacterial skin and soft tissue infections in adults: A review of their epidemiology, pathogenesis, diagnosis, treatment and site of care. Can J Infect Dis Med Microbiol,19(2),, 2008, 173-84.

[7]. Dryden MS. Complicated skin and soft tissue infection. J AntimicrobChemother,65(3),2010, 35-44.

[8]. Ramana KV, Pinnelli VB, Prakash B, Silvia WD, Kandi S, Sharada CV et al. Complicated Skin and Skin structure infections (cSSSI's): A Comprehensive Review. Am J Med Biolog Res, 1(4),2013, 159-164.

[9]. Collee JG, Dugaid JP, Fraser AG, Marmion BP, Simmons A, Laboratory strategy in the diagnosis of infective syndromes. In: Collee JG, Fraser AG, Marmion BP, Simmons A (Ed). Mackie and McCartney practical medical microbiology14 ${ }^{\text {th }}$ ed( Churchill Livingstone, 2006) 53-94.

[10]. Winn WC, Allen SD, Janda WM, Koneman EW, Procop GW, Schreckenberger PC, Woods GL, Introduction to microbiology. In Koneman's Color Atlas and Textbook of Diagnostic Microbiology6 ${ }^{\text {th }}$ Ed (Philadelphia: Lippincott Williams \& Wilkins, 2006) 67110 .

[11]. Bauer AW, Kirby WMM, Sherris JC, Turck M. Antibiotic susceptibility testing by a standardized single disk method. Am J ClinPathol45, 1966, 493-496.

[12]. Clinical and Laboratory Standards Institute. Performance standards for antimicrobial susceptibility testing; Twenty fourth informational supplement. 2014; M100-S24. Wayne, PA

[13]. Black JA, Moland ES, Thomson KS. Amp C disk test for detection of plasmid mediated Amp C $\beta$ - lactamases in Enterobacteriaceae lacking chromosomal Amp C beta-lactamases. J ClinMicrobiol43(7),2005,3110-3113.

[14]. Kolhapure RM, Kumar A, Rajkumar HRV. Coexpression of ESBL, Amp C and MBL in gram negative bacilli. Int J Res Med Sci3(10), 2015, 2698-2703.

[15]. Yong D, Lee K, Yum JH, Shin HB, Rossolini GM, Chong Y. Imipenem-EDTA disk method for differentiation of metallo $\beta$ lactamases producing clinical isolates of Pseudomonasspp and Acinetobacter spp. J ClinMicrobiol 40, 2002, 3798-3801.

[16]. El-Kazzaz SS, El-khier NT. Amp C and metallo $\beta$-lactamases producing Gram negative bacteria in patients with hematological malignancy. Afr J MicrobiolRes 9(18), 2015, 1247-1254.

[17]. Joshi S, Ray P, Manchanda V, Bajaj J, Chitnis DS, Gautam V et al. Methicillin resistant Staphylococcus aureus (MRSA) in India: Prevalence \& susceptibility pattern. Indian J Med Res 137, 2013, 363-369.

[18]. Uzunovic S, Bedenic B, Budimir A, Ibrahimagic A, Kamberovic F, Fiolic Z et al. Methicillin-resistant S. aureus (MRSA), extended-spectrum (ESBL) and plasmid mediated AmpC $\beta$-lactamase producing Gram-negative bacteria associated with skin and soft tissue infections in hospital and community settings. Med Glas (Zenica) 12(2), 2015, 157-168.

[19]. Goyal A, Diwakar MK, Bhooshan S, Goyal S, Agrawal A. Prevalence and Antimicrobial Susceptibility Pattern of Methicillinresistant Staphylococcus aureus [MRSA] isolates at a Tertiary Care Hospital in Agra, North India- A systemic annual review. IOSR J Dental and Med Sciences 11(6), 2013, 80-84.

[20]. Sharma A, Gupta S. Aerobic bacteriological profile of skin and soft tissue infections (SSTI's) and its antimicrobial susceptibility pattern at M.B. Govt Hospital in Udaipur, Rajasthan. Int J Med Sci Edu 3(2), 2016, 141-151.

[21]. Dessie W, Mulugeta G, Fentaw S, Mihret A, Hassen M, Abebe E. Pattern of bacterial pathogens and their susceptibility isolated from surgical site infections at selected referral hospitals, Addis Ababa, Ethiopia. Int J Microbiol 2016. http:dx.doi.org/10.1155/2016/2418902.

[22]. Afroz Z, Metri BC, Jyothi P. Bacteriological profile and antimicrobial susceptibility pattern of skin and soft tissue infections among gram negative bacilli in a tertiary care hospital of South India. J Pharm Sci\& Res 7(7), 2015, 397-400.

[23]. Thomson KS. Extended Spectrum $\beta$ - Lactamase, AmpC and Carbapenemase Issues. J ClinMicrobiol 48(4), 2010, 1019-1025.

[24]. Ranjini CY, Rangasamy VR. Detection of ESBL and plasmid mediated AmpCbetalactamases among the Gram negative bacterial isolates in diabetic foot ulcer infections. Community Acquired Infection 2(2), 2015, 57-62.

[25]. Vishwanath S, Shwetha PS, Sushma M, Bairy I, Mukhopadhyay C. Extended Spectrum $\beta$ - lactamase production among Enterobacter cloacae and Enterobacter aerogenes at a tertiary care center in Coastal Karnataka. Nat J Lab Med 5(3), 2016, M001M004.

[26]. Manikandan P. Detection of $\beta$-lactamase mediated resistance among Pseudomonas aeruginosa isolates from ocular infections. Nat $\mathbf{J}$ Lab Med 5(1), 2016, 12-16. 
[27]. Fish DN. Meropenem in the treatment of complicated skin and soft tissue infections. Therapeutics and Clinical Risk Management 2(4), 2006, 402-415.

[28]. Agarwal S, Kakati B, Khanduri S, Gupta S. Emergence of Carbapenem resistant Non-fermenting gram negative bacilli isolated in an ICU of a tertiary care hospital. J Clinical and Diagnostic Research 11(1), 2017, DC04-DC07.

[29]. Chavan SP, Shrikhande SN, Prasad RR, Gajbhiye SR. Detection of various $\beta$-lactamases amongst gram negative bacilli from clinical isolates with special reference to Metallo $\beta$-lactamases. Int J Adv Res 4(5), 2016, 22-29.

[30]. Manoharan A, Barla GS, Peter R, Sugumar M, Mathai D. Multidrug resistance mediated by co-carriage of extended spectrum $\beta$ lactamases, AmpC and New Delhi metallo-beta-lactamase-1 genes among carbapenem-resistant Enterobacteriaceae at five Indian medical centres. Ind J Med Microbiol 34(3), 2016, 359-361. 